BOSQUE 25(2): 3, 2004

PALABRAS DEL EDITOR

\title{
Divulgación del conocimiento científico: un aporte al desarrollo
}

Divulgation of the scientific knowledge: a contribution to the development

\author{
SILVANA MARIANI A.
}

M.Sc. Productos Forestales

Las exportaciones del sector forestal chileno siguen en auge gracias al esfuerzo conjunto del sector público y el privado. El patrimonio y disponibilidad de madera son crecientes y el sector avanza en el desarrollo sustentable de la actividad; sin embargo, este desarrollo está asociado a la capacidad profesional, ética y valórica de cada uno de los actores para incrementar la productividad y aprovechamiento del recurso.

Un aporte muy importante lo realizan la investigación, la búsqueda de mejores tecnologías y la divulgación de estos conocimientos a todo el sector forestal. En este sentido, SILVOTECNA tiene como misión fundamental analizar, transferir y difundir los resultados de la ciencia y tecnología aplicadas a la silvicultura, reuniendo expertos de primer nivel, tanto de empresas como instituciones forestales nacionales e internacionales.

SILVOTECNA es un evento que se realiza en Chile desde 1994, organizado por la Corporación Chilena de la Madera (CORMA). Esta Corporación reúne a empresas, profesionales, ejecutivos y personas naturales relacionadas con el sector forestal chileno, representando a empresas de forestación y transformación de la madera (aserrío, celulosa, tableros y remanufactura).

Es así como este número de BOSQUE ha sido orientado a la divulgación de algunos de los temas tratados en la XVIII SILVOTECNA, realizada en la ciudad de Concepción, Chile, el 11 y 12 de noviembre de 2003, cuyo tema central fue Aumento de rentabilidad en plantaciones de pinos y eucaliptos: mejoramiento en calidad de plantas y productividad de sitios.

El aumento y generación de nuevo conocimiento permitirá un mejoramiento continuo en la actividad forestal chilena. 